\title{
Factors influencing the utilization of family planning services among HIV infected women in a Kenyan health facility
}

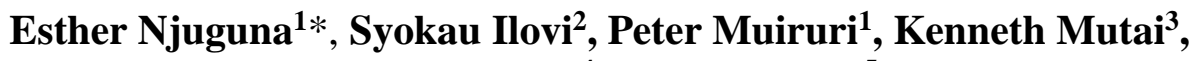 \\ John Kinuthia ${ }^{4}$, Peter Njoroge ${ }^{5}$
}

${ }^{1}$ Comprehensive Care Center, ${ }^{4}$ Department of Research and Programs, Kenyatta National Hospital, Nairobi, Kenya ${ }^{2}$ Department of Medicine and Therapeutics, ${ }^{3}$ Partners in Advanced Care and Treatment PACT, ${ }^{5}$ School of Public Health, University of Nairobi, Nairobi, Kenya

Received: 06 March 2017

Accepted: 01 April 2017

\section{*Correspondence:}

Dr. Esther N. Njuguna,

E-mail: njugunadr@gmail.com

Copyright: ( ) the author(s), publisher and licensee Medip Academy. This is an open-access article distributed under the terms of the Creative Commons Attribution Non-Commercial License, which permits unrestricted non-commercial use, distribution, and reproduction in any medium, provided the original work is properly cited.

\section{ABSTRACT}

Background: Women's knowledge and access to reproductive health services improves their ability to safely achieve their required fertility and reduces maternal and infant morbidity and mortality. We aimed to determine the utilization of family planning (FP) among HIV Infected women visiting the HIV clinic.

Methods: A cross-sectional mixed quantitative and qualitative study among HIV positive females in Nairobi, Kenya was conducted. Consenting women completed a questionnaire that assessed the utilization of FP services. Descriptive and inferential analysis was carried out on quantitative data to determine significant associations with FP utilization. Qualitative data were analyzed after coding for significant clauses and transcribing to determine themes arising.

Results: We enrolled a total of 387 patients, mean age (IQ range) 40 years (36-44). The contraceptive prevalence was $53 \%$ with an unmet need of family planning of $38.5 \%$. Patients were more likely to use family planning if they were married, if condoms were offered at the clinic, if they discussed contraception with the clinic staff and their partners. They were less likely to use FP if they had expressed fertility desire. Widows were less likely to use any form of FP than married couples despite having sexual partners. The main themes on the barriers of utilization of family planning services included lack of knowledge, pill burden, and adverse reactions to hormonal FP.

Conclusions: The unmet need of family planning is high, and heightened measures need to be taken to improve the utilization of the service. Particular groups such as sexually active widows and single women should be targeted for these interventions.

Keywords: Family Planning, Human immunodeficiency virus, Women

\section{INTRODUCTION}

Globally 34 million people are living with HIV, two thirds of who reside in Sub-Saharan Africa. Of these, $56 \%$ are women. Similarly, in Kenya, $60 \%$ of the estimated 1.5 million HIV infected people are women. Children estimated to be HIV infected globally are 3.4 million, with Kenya contributing about 180,000 to the burden of disease. ${ }^{1}$
There has been an escalating demand for family planning (FP) by HIV-positive women in reproductive age group who are now living longer primarily because of readily available and effective combination antiretroviral therapy. ${ }^{2-4}$ Integrated reproductive health and HIV services have been recommended as a cost effective strategy to prevent mother to child transmission. ${ }^{5-8}$ Regardless of HIV status, women's knowledge and access to reproductive health services improves their 
ability to safely achieve their required fertility and reduces maternal and infant morbidity and mortality. ${ }^{9,10,11}$ This is because they are able to delay pregnancies until they are ready, and seek early prenatal services once they get pregnant. In HIV infected women, it is estimated that the levels of unintended pregnancies range from about $51-90 \%$ based on anecdotal reports, formal questionnaires and interviews of women enrolled in PMTCT programs (in Rwanda, rural Eastern Uganda, rural South Africa and the Côte d'Ivoire), ranging over a period of 2 years from post-natal follow-up. ${ }^{7}$

The Centers for Disease Control and Prevention (CDC) defines unintended pregnancies as a pregnancy that is either mistimed or unwanted at the time of conception. ${ }^{12,13}$ Unintended pregnancies pose as a big problem to HIV affected communities. An estimated $90 \%$ of new HIV infections among children under the age of 15 are a result of mother-to-child transmission of HIV. ${ }^{14}$ Every year, about 120,000 HIV infected women become pregnant many of who were not intending to get pregnant. ${ }^{15}$ Another consequence of unintended pregnancies is induced abortions. In Kenya, it is estimated that there are 46 abortions for every 1,000 women of reproductive age, or about 29 for every 100 live births. ${ }^{16}$ Unsafe abortion is a major public health crisis in Kenya, accounting for $35 \%$ of Kenya's maternal deaths. ${ }^{16}$

The reasons for unintended pregnancies have been studied and include non-use of contraceptive methods, poor adherence to contraception and contraceptive failure. ${ }^{17}$ Several studies have suggested that HIV infected women are more likely to report that their pregnancies are unintended, mainly because of provider attitude and the fear for disappointment from the health provider. ${ }^{18,19}$ Modern contraception is defined by the WHO to include female sterilization, oral contraceptive pills, injection, implants, depo provera or condoms as a method to prevent pregnancy. ${ }^{20,21}$

The contraceptive prevalence is the percentage of women aged 15 to 49 who are currently using, or whose sexual partner is currently using, at least one method of contraception. There has been a growing trend in the contraception prevalence in Kenya from 4.4\% in 1977/78 to currently $39 \%$ in $2008 / 09$, with unmet need for family planning standing at $26 \%$ in $2008 / 09$ down from $38 \%$ in 1988/89. ${ }^{22}$ However, among HIV infected women the unmet need for family planning is $30 \%$ a situation thought to be because of erroneous provider perception that HIV infected women should not use modern contraception particularly hormonal method. ${ }^{23,20}$ Previous studies on the utilization of family planning services by HIV infected women have demonstrated that knowledge of the importance of contraception was grossly lacking and lack of integrated FP and HIV services has also contributed to failure in accessing FP methods despite the desire to do so. ${ }^{24,7} \mathrm{We}$ sought to determine the factors influencing the utilization of FP services in Kenyatta National Hospital (KNH), Comprehensive Care Center (CCC).

\section{METHODS}

\section{Study area}

This was a cross-sectional study targeting women on follow up at $\mathrm{CCC}$ in $\mathrm{KNH}$, a National Referral Hospital in Nairobi, Kenya. The clinic caters to close to 6,000 HIV infected people, $60 \%$ of whom are women. It provides free Anti-Retroviral Therapy as well as treatment for Opportunistic Infections.

\section{Variables}

The outcome variable was the utilization of FP services in the last 2 years.

\section{Study population}

The study targeted HIV-infected women between 18 and 49 years of age who had been followed up at the HIV clinic for not less than 2 years.

\section{Study procedures}

\section{Qualitative arm}

Purposive sampling of the study population was conducted for the qualitative arm of the study. Eligible participants were approached by a trained counselor in the clinic and requested if they are interested in participating in the study. Those who accepted were then enrolled for Focus Group Discussions (FGDs) using key indicators including age and parity. Different groups based on age were determined to avoid mixing older women with younger women as this may have influenced their honest response to the sensitive questions.

\section{Quantitative arm}

Systematic random sampling for the quantitative arm of the study was done and interviewer administered structured questionnaires administered. Every $5^{\text {th }}$ female patient was screened to ensure they met the eligibility criteria of (1) age above 18 years, (2) enrollment into the clinic of not less than 2 years and (3) ability to consent. Those eligible were consented in their preferred language, either English or Kiswahili, before a structured questionnaire was administered by a trained research assistant.

\section{Data collection and analysis}

\section{Qualitative data collection}

Four FGDs each with 6-8 participants based on the principles of qualitative research each lasting 60-90 minutes were conducted. Group conduct included 
maintaining confidentiality by ensuring that each participant was identified by number and not by name. ${ }^{26}$ Social demographic characteristics and key information on participant's age, parity and current use of family planning were taken prior to the FGD. The discussion was conducted and recorded using a digital recorder in the preferred language either English or Kiswahili which was translated later into English. A note taker was present during all the session and notes taken for comparison with the digital recordings.

Coding for key clauses was done using a code book before transcription. This was done by two people- the Principal Investigator and a trained research assistant. To validate the quality of translation and transcription, 50\% of the transcripts were compared with the translation. The participants involved in the qualitative data collection were not required to participate in the quantitative data collection.

\section{Quantitative data collection}

We used structured interviewer administered questionnaires to determine the socio-demographic characteristics of the participants and factors influencing the utilization of FP. Descriptive and inferential analysis were done using chi square tests to determine the association between cervical cancer screening and other socio-demographic characteristics with a two-sided pvalue and alpha value of 5\%. For statistically significant associations, logistic regression odds ratio was calculated to control for confounders and determine the strength of association.

\section{RESULTS}

A total of 387 participants were enrolled in the period January 2013 to April 2013. The median age was of40 (Inter Quartile Range of 36-44 years) (Table 1).

The contraception prevalence of participants currently using a form of family planning is $53 \%$, while $76 \%$ reported to have used a modern method of family planning in their lifetime. The unmet need for family planning was $38.5 \%$ with a 2 -year pregnancy intention of $27 \%$. Patients were more likely to use family planning if they were married (OR 12.9 CI 6.5-25.7; p-value <0.01), if condoms were offered at the clinic (OR 3.2, CI 1.9-5.4, $\mathrm{p}<0.001)$, and if they discussed contraception with the clinic staff (OR 3.4 CI 2.2-5.4, p-value <0.001) and their partners (OR 2.6, CI 1.7-4.0, p <0.001). They were less likely to use FP if they had expressed fertility desire (OR 3.0, CI 1.8-4.8 p-value <0.001). Multivariate analysis showed significant use of FP if the participant had a twoyear pregnancy intention (AOR 4.1, 95\% CI 1.7-9.8, p $<0.001)$, and if they had discussed contraception with a staff member (AOR 2.1, 95\% CI.0-4.6, $\mathrm{p}=0.002$ ). Widows were less likely to use any form of FP than married couples despite having sexual partners (AOR 0.1, 95\% CI 0.04-0.2, p <0.001). Similarly, single and divorced women were less likely to use FP than married women (AOR 0.1, 95\% CI 0.03-0.3, p <0.001) and (AOR $0.4,95 \%$ CI 0.02-0.1, $\mathrm{p}<0.001$ ) respectively (Table 2).

Table 1: Selected socio-demographic characteristics of enrolled HIV infected women.

\begin{tabular}{|lll|}
\hline Characteristics & N & $\%$ \\
\hline Occupation & & \\
\hline Employed & 116 & 30.0 \\
\hline Self employed & 196 & 50.6 \\
\hline Not employed & 75 & 19.4 \\
\hline Level of education & & \\
\hline No education & 6 & 1.5 \\
\hline Primary & 111 & 28.6 \\
\hline Secondary & 180 & 46.4 \\
\hline Tertiary & 90 & 23.5 \\
\hline Marital Status & & \\
\hline Single (never married) & 63 & 16.3 \\
\hline Married & 165 & 42.6 \\
\hline Widow & 81 & 20.9 \\
\hline Divorced/separated & 78 & 20.2 \\
\hline Currently having a partner & 238 & 61.4 \\
\hline HIV status of partner (n=238) & & \\
\hline HIV Infected & 110 & 46.2 \\
\hline HIV uninfected & 67 & 28.2 \\
\hline Don't know & 61 & 25.6 \\
\hline Partners last 6 months & & \\
\hline 0 & 140 & 36.3 \\
\hline 1 & 243 & 63 \\
\hline 2 & 2 & 0.5 \\
\hline 4 & 1 & 0.3 \\
\hline
\end{tabular}

Most participants (43.7\%) stopped using family planning for no serious reason, while $41 \%$ stopped using because of side effects and 10\% desired fertility. On pregnancy outcome for the participants who had ever gotten pregnant since joining the clinic, the study showed that the number of HIV infected children were $42(10.8 \%)$, with more than half $(54 \%)$ being unintended. Therefore, more than $50 \%$ of pregnancies whose outcome was HIV infected children were actually unplanned or unintended. Barriers to accessing FP services were determined by qualitative data included the following:

\section{Lack of knowledge}

Some participants did not know about dual contraception and assumed that use of condoms alone is sufficient. However, majority of the participants were not using family planning as they did not desire to have a child in the next 2 years. The participants generally did not use hormonal methods of family planning together with condoms as they did not think this was necessary. "I thought using a condom alone is fine. I did not know that one must use more than one method at the same time" 33-year-old lady, "I have irregular periods and so I did not know that I should also use another method of family planning" 40-year-old lady. 
Table 2: Correlates of FP utilization among women attending KNH CCC.

\begin{tabular}{|c|c|c|c|c|}
\hline \multirow{2}{*}{ Characteristics } & \multicolumn{2}{|c|}{ Currently using FP } & \multirow{2}{*}{ OR $(95 \% \mathrm{CI})$} & \multirow{2}{*}{ P-Value } \\
\hline & Yes n (\%) & No n $(\%)$ & & \\
\hline \multicolumn{5}{|l|}{ Occupation $n=385$} \\
\hline Not employed & $39(52.0)$ & $36(48.0)$ & $0.9(0.6-1.5)$ & 0.69 \\
\hline Employed & $169(54.5)$ & $141(45.5)$ & 1.0 & \\
\hline \multicolumn{5}{|l|}{ Level of education $n=386$} \\
\hline No education & $2(33.3)$ & $4(66.7)$ & 1.0 & \\
\hline Primary & $56(50.9)$ & $54(49.1)$ & $2.1(0.4-11.8)$ & 0.679 \\
\hline Secondary & $101(56.1)$ & $79(43.9)$ & $2.5(0.4-20.3)$ & 0.410 \\
\hline Tertiary & $49(54.9)$ & $41(45.6)$ & $2.3(0.4-13.7)$ & 0.4141 \\
\hline \multicolumn{5}{|l|}{ Marital status $n=385$} \\
\hline Single (Never married) & $21(33.3)$ & $42(66.7)$ & 1.0 & \\
\hline Married & $142(86.6)$ & $22(13.4)$ & $12.9(6.5-25.7)$ & $<0.001$ \\
\hline Widow & $17(21.0)$ & $64(79.0)$ & $0.5(0.3-1.1)$ & 0.127 \\
\hline Divorced/separated & $27(35.1)$ & $50(64.9)$ & $1.1(0.5-2.2)$ & 0.860 \\
\hline \multicolumn{5}{|l|}{ HIV status partner $n=235$} \\
\hline HIV Infected & $94(86.2)$ & $15(13.8)$ & 1.0 & \\
\hline HIV uninfected & $60(90.9)$ & $6(9.1)$ & $1.6(0.6-4.3)$ & 0.360 \\
\hline Don't know & $49(81.7)$ & $11(18.3)$ & $0.7(0.3-1.7)$ & 0.432 \\
\hline \multicolumn{5}{|l|}{ Ever used FP before $n=385$} \\
\hline Yes & $159(54.5)$ & $133(45.5)$ & $1.1(0.7-1.8)$ & 0.632 \\
\hline No & $48(51.6)$ & $45(48.4)$ & 1.0 & \\
\hline \multicolumn{5}{|l|}{ Method of FP used n=292 } \\
\hline Male condoms & $6(3.8)$ & $10(7.5)$ & $0.5(0.2-1.4)$ & 0.199 \\
\hline Coil & $11(6.9)$ & $14(10.5)$ & $0.6(0.3-1.4)$ & 0.299 \\
\hline Oral contraception pills & $42(26.4)$ & $34(25.6)$ & $1.0(0.6-1.8)$ & 0.894 \\
\hline 3-month injection & $86(54.1)$ & $63(47.4)$ & $1.3(0.8-2.1)$ & 0.290 \\
\hline Norplant & $9(5.7)$ & $5(3.8)$ & $1.5(0.5-4.7)$ & 0.585 \\
\hline Coil and oral contraception pill & $1(<1)$ & $6(4.5)$ & $0.1(0-1.1)$ & 0.050 \\
\hline Norplant and oral contraception pill & $4(2.5)$ & $1(<1)$ & $3.4(0.4-31.1)$ & 0.380 \\
\hline \multicolumn{5}{|c|}{ Condoms offered at $\mathrm{CCC}$ last 2 yrs $n=375$} \\
\hline Yes & $178(61.0)$ & $114(39.0)$ & $3.2(1.9-5.4)$ & $<0.001$ \\
\hline No & $27(32.5)$ & $56(67.5)$ & 1.0 & \\
\hline \multicolumn{5}{|c|}{ FP Services offered at CCC last 2 yrs $n=384$} \\
\hline Yes & $128(57.7)$ & $94(42.3)$ & $1.4(1.0-2.2)$ & 0.084 \\
\hline No & $79(48.8)$ & $83(51.2)$ & 1.0 & \\
\hline \multicolumn{5}{|c|}{ Advisable use of other methods other than condoms $n=383$} \\
\hline Yes & $129(57.1)$ & $97(42.9)$ & $1.4(0.9-2.0)$ & 0.153 \\
\hline No & $78(49.7)$ & $79(50.3)$ & 1.0 & \\
\hline \multicolumn{5}{|c|}{ Intend to get pregnant in next 2 years $n=377$} \\
\hline Yes & $74(72.5)$ & $28(27.5)$ & $3.0(1.8-4.8)$ & $<0.001$ \\
\hline No & $130(47.3)$ & $145(52.7)$ & 1.0 & \\
\hline \multicolumn{5}{|l|}{ Any HIV infected children $n=375$} \\
\hline Yes & $26(61.9)$ & $16(38.1)$ & $1.5(0.8-2.8)$ & 0.267 \\
\hline No & $176(52.9)$ & $157(47.1)$ & 1.0 & \\
\hline \multicolumn{5}{|c|}{ Discussed contraceptives with staff $n=384$} \\
\hline Yes & $99(72.3)$ & $38(27.7)$ & $3.4(2.2-5.4)$ & $<0.001$ \\
\hline No & $107(43.3)$ & $140(56.7)$ & 1.0 & \\
\hline \multicolumn{5}{|c|}{ Discussed contraceptives with partner $n=361$} \\
\hline Yes & $141(66.8)$ & $70(33.2)$ & $2.6(1.7-4.0)$ & $<0.001$ \\
\hline No & $66(44.0)$ & $84(56.0)$ & 1.0 & \\
\hline
\end{tabular}

\section{Pill burden}

As the participants are on other medication, they felt that using hormonal contraception will increase the side effects of the drugs that they are using. Some participants opted for natural method as opposed to using a hormone. 
"I only use condoms alone as I was worried about using both hormonal method of family planning together with my ARVs. Unfortunately, I got an unplanned pregnancy following a burst condom, though the baby is HIV negative" 44-year-old lady.

\section{Side effects of hormonal contraception}

Several participants had previously used hormonal contraceptive methods but suffered side effects in particular bleeding and weight gain, therefore discouraging them from using the methods again.

"I do not use hormonal methods as when I last used them I bled for a long time. I do not want to go back to having that problem again" 39-year-old lady.

"I used FP for 2 years and gained a lot of weight. When I removed, it I bled for so long. That is why I do not use a family planning method" 41-year-old lady.

\section{DISCUSSION}

The contraceptive prevalence in this study was $53 \%$. This was comparable to a study done to determine the utilization of family planning services among HIV infected women in Ethiopia where $56.7 \%$ of the respondents were using a modern method of family planning. However, no participant in this study was on dual contraception compared to $30 \%$ of those using contraception in the Ethiopia study. ${ }^{26}$

The contraceptive prevalence in this study is however higher than the general country prevalence of $39 \%$ in $2008 / 2009$, with the unmet need for family planning of $38.5 \%$ compared to the general country estimate of $25 \%$ in $2008 .^{22,2,27}$

On comparing the contraceptive prevalence and unmet need for family planning among HIV infected people, this study has a lower unmet need for family planning compared to the country estimate of about $60 \% .^{2}$ About $72.8 \%$ of the participants responded that they did not have pregnancy intention in the next two years, with only about $53.9 \%$ currently using a method of family planning. A previous study done in KNH CCC in 2008 found that $86 \%$ of the respondents did not have pregnancy intention with only $44.2 \%$ participants actually using a method of family planning and an unmet need for family planning of $30 \% .^{28}$ Very little in terms of pregnancy intention, unmet need for family planning and contraceptive prevalence have changed since the study in 2008.

The factors which were significantly associated with use of family planning in this study included marital status, occupation, HIV status of the partner, issuance of condoms in the clinic, pregnancy intention and whether the participant discussed contraceptive methods with the clinic staff or their partner.
Seventy eight percent of the participants had been offered condoms in the clinic, but only $59 \%$ of them were offered dual contraception. In the study by Mutiso et al in 2008, he found that only $10 \%$ of the participants were actually getting their condoms from the CCC. ${ }^{23}$ This therefore shows a great improvement as the figure has increased to $78 \%$.

The HIV status of the participants did not influence the use of family planning in this study. This provides an opportunity for intervention for discordant couples particularly as it would be expected that having a HIV uninfected partner would be a motivator for consistent condom use. Similar findings were reported in a study done in Kisumu where a high number of pregnancies occurred among HIV discordant couples, indicating that the need to conceive may be the reason condom use is very low among the couples. ${ }^{29}$

Widows were significantly less likely to use a method of family planning than married women despite having sexual partners. Similar findings were reported in a study in South Western Uganda. ${ }^{30}$ This finding however should be taken with concern, mainly because the usual assumption is that single and widowed women are not in need for contraceptive methods, yet the truth is that they may be engaging in unprotected sexual encounters, putting them at risk of STIs or unplanned pregnancies. ${ }^{31}$ They therefore represent a vulnerable group in need of a direct and specific intervention.

Issuance of condoms in the clinic increased likelihood of participants using them. Similarly discussing contraceptives with the clinic staff significantly increased the likelihood of using contraception, a finding shared with several studies in Gambia and Cambodia. ${ }^{26,32}$ This is because the clinic staffs that have direct contact with the patient are able to influence their choices, primarily by provision of health education. This has programmatic implications in support of FP integration in the ART clinic as patients would prefer a one stop shop for provision of HAART as well as their FP needs as indicated in a study done in Uganda and Kenya. ${ }^{33,34}$

Discussion of contraceptive use with the partner also increased the likelihood that the participant was on a contraceptive method. The influence of the male partner to women taking up family planning methods has also been shown in several studies across East Africa. ${ }^{35-37}$

Pregnancy outcomes among HIV infected women in a study conducted in Kisumu showed that $59 \%$ of pregnancies were unintended. ${ }^{37}$ The estimates of unintended pregnancies among HIV infected women are about 51-91\% implying a poor uptake of Reproductive health services in HIV programs. ${ }^{38}$ Fewer unintended pregnancies reduces the chances of mother to child transmission and hence fewer children born with HIV. 


\section{CONCLUSION}

The unmet need of family planning is unacceptably high, and heightened measures need to be taken to improve the utilization of the service. Particular groups such as sexually active widows, single and divorced women should be targeted for these interventions. The main barriers arising included Pill burden, lack of knowledge and fear of side effects of hormonal contraception.

\section{ACKNOWLEDGEMENTS}

Author would like to thank the Kenyatta National Hospital, Department of Research and Programs for funding and facilitating the success of this research. Author would also like to acknowledge the HIV care and treatment clinic in Kenyatta National Hospital management, staff and the patients enrolled in this study for their support and cooperation during the study period

Funding: Kenyatta National Hospital, Department of Research and Programs

Conflict of interest: None declared

Ethical approval: The study was approved by the University of Nairobi/Kenyatta National Hospital Ethics Review Committee (ERC)

\section{REFERENCES}

1. UNAIDS World AIDS Day Report, Global estimates UNAIDS; 2011.

2. Kenya Demographic Health Survey; 2008-2009.

3. Kaloustian KW, Kimaiyo S, and Lameck D. Viability and effectiveness of large-scale HIV treatment initiatives in sub-Saharan Africa: experience from western Kenya. 2006;20(1)41-8.

4. Delaney KM, Moorman AC, Palella FJ. Declining Morbidity and Mortality among Patients with Advanced Human Immunodeficiency Virus Infection. 1998;338:853-60.

5. World Health Organization Reproductive Health Website, Prevention of mother-to-child transmission of HIV (PMTCT) and family planning (FP); 2012.

6. Lush L, Cleland J, Walt G, Mayhew S. Integrating reproductive health: myth and ideology. BulletinWorld Health Organization. 1999;77:771-7.

7. Wilcher, Rose, and Willard Cates. "Reproductive choices for women with HIV." Bulletin of the World Health Organization 87.11 (2009): 833-839.

8. WHO/UN FPA/UNA IDS/IPPF. Sexual and Reproductive Health and HIV/AIDS. A Framework for Priority Linkages; 2005.

9. World Health Organization Reproductive Health website, "New national-level core indicator for monitoring and evaluating family planning aspect of PMTCT programmes; 2012.

10. Singh S. Adding it all up: The costs and benefits of investing in family planning and maternal and newborn health; 2009.
11. Best K. Best K. Family planning and the prevention of mother-to-child transmission of HIV: a review of the literature; 2004.

12. The Centers for Disease Control and prevention website, Unintended Pregnancy Prevention; 2012.

13. World Health Organization. Interagency Task Team on Prevention of HIV infection in pregnant women. Towards Universal Access for Women, Infants and Young Children and Eliminating HIV and Aids Among Children; 2007.

14. K 4 Health Website on prevention of mother to child transmission, Preventing Unintended Pregnancies Among HIV-Positive Women; 2012.

15. Amy E Pollack, Family Planning and HIV: a close look at Kenya; 2012.

16. The Guttmacher Institute, Unsafe Abortion in Kenya. Available from: http://www.guttmacher.org/pubs/FB_Abortion-inKenya.pdf, no. Accessed on 1st April 2012, 2008.

17. Harper CC, and Shields WC, Speidel JJ, The Potential of Long-acting Reversible Contraception to Decrease Unintended Pregnancy, Available from: http://www.arhp.org/publications-and resources/contraception-journal/september,no.

18. Carolyn B, Rutenberg N. Addressing the family planning needs of HIV-positive PMTCT clients: Baseline findings from an operations research study; 2005.

19. Reynolds HW, Steiner MJ, Cates W. Contraception's proved potential to fight HIV. 2005;81(2):184-5.

20. The World Health Organization website, WHO upholds guidance on hormonal contraceptive use and HIV; 2012.

21. Mwapasa V, "Maternal syphilis infection is associated with increased risk of mother-to-child transmission of HIV in Malawi. 2006;20:1869-77.

22. United Nations, Department of Economic and Social Affairs, Population Division, World Contraceptive Use. 2010; 2011.

23. Mutiso SM, Kinuthia J, Qureshi Z. Contraceptive use among HIV infected women attending Comprehensive Care Centre. 2008;85(4):171-7.

24. Marahatta R, Tuladhar H. Awareness and practice of family planning methods in women attending gyne OPD at Nepal Medical College Teaching Hospital. 2008;10(3):184-91.

25. Sandelowski M. Sample size in qualitative research Research in Nursing and Health; 1995.

26. Polisi A. Modern contraceptive utilization among female ART attendees in health facilities of Gimbie town. Reproductive Health; 2014.

27. Division of Public and Reproductive Health, National Family Planning Guidelines for Service Providers; 2010.

28. Mutiso SM, Kinuthia J, Qureshi Z. Contraceptive use among HIV infected women attending Comprehensive Care Centre. 2008;85(4):171-7.

29. SG Brubaker, EA Bukusi, J Odoyo, J Achando, A Okumu and CR Cohen, Pregnancy and HIV 
transmission among HIV-discordant couples in a clinical trial in Kisumu, Kenya. 2010;1.

30. Muyindike W, Fatch R, Steinfield R, Lynn T. Matthews. Contraceptive Use and Associated Factors among Women Enrolling into HIV Care in Southwestern Uganda. 2012;340782:9.

31. Chibwesha CJ, Li MS, Matoba CK, Mbewe RK, Chi $\mathrm{BH}$, Stringer JS, et al. Modern contraceptive and dual method use among HIV-infected women in Lusaka, Zambia. Infectious diseases in obstetrics and gynecology; 2011.

32. Nakaie N, Tuon S, Nozaki I, Yamaguchi F, Sasaki Y, Kakimoto K. Family planning practice and predictors of risk of inconsistent condom use among HIVpositive women on anti-retroviral therapy in Cambodia. BMC public health. 2014;14(1): 170.

33. Asiimwe D, Kibombo R, Matsiko J, Hardee K. Study of the Integration of Family Planning and VCT/PMTCT/ART Programs in Uganda. Institute of Social Research and the POLICY Project; 2005.

34. Steinfeld RL, Newmann SJ, Onono M, Cohen CR, Bukusi EA, Grossman D. Overcoming Barriers to Family Planning through Integration: Perspectives of HIV-Positive Men in Nyanza Province, Kenya; 2013.

35. Enqueselassie F, Haile A. "Influence of women's autonomy on couple's contraception use in Jimma town, Ethiopia. 2006;20(3):1-7.
36. Muyindike W, Fatch R, Steinfield R, Matthews LT, Musinguzi N, Emenyonu NI, et al. Contraceptive Use and Associated Factors among Women Enrolling into HIV Care in Southwestern Uganda. 2012:1-9.

37. Akelo V, Girde S, Borkowf CB, Angira F, Achola K, Lando R, et al. Attitudes toward family planning among HIV-positive pregnant women enrolled in a prevention of mother-to-child transmission study in Kisumu, Kenya. PloS one. 2013;8(8):66593.

38. Hoffman IF, Martinson FE, Powers KA, Chilongozi DA, Msiska ED, Kachipapa EI, et al. The year-long effect of HIV-positive test results on pregnancy intentions, contraceptive use, and pregnancy incidence among Malawian women. JAIDS Journal of Acquired Immune Deficiency Syndromes. 2008;47(4):477-83.

Cite this article as: Njuguna E, Ilovi DS, Muiruri P, Mutai K, Kinuthia J, Njoroge P. Factors influencing the utilization of family planning services among HIV infected women in a Kenyan health facility. Int J Reprod Contracept Obstet Gynecol 2017;6:1746-52. 